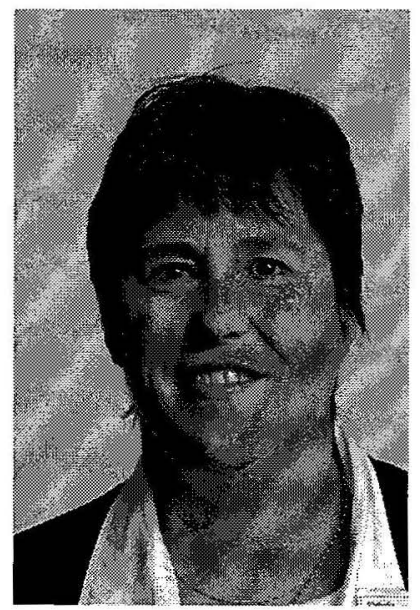

\title{
HAVE COMPUTERS \\ CHANGED THE NEW \\ ZEALAND WAGE \\ STRUCTURE? EVIDENCE FROM DATA ON TRAINING
}

\author{
Bridget Daldy and John Gibson ${ }^{1}$ \\ Department of Economics, Waikato \\ Management School, Waikato University
}

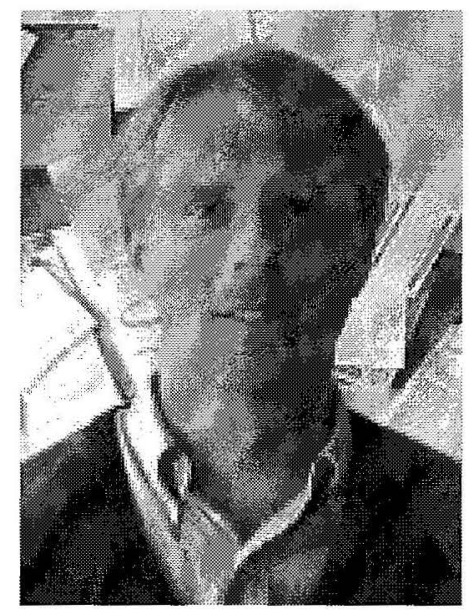

\begin{abstract}
One of the reasons why inequality in earnings may have widened in recent years is due to technological changes, which include the wider use of computers within the workplace. Partly as a result, the current Government is keen on encouraging people to obtain the computer skills required to enable them to be part of the modern economy. A number of international studies have shown that workers who use a computer at work earn more than workers who do not. While large-scale survey data on wages and computer use in New Zealand are unavailable it is possible to examine the effect on wages of receiving computer-related training. The results from the 1996 Education and Training Survey suggest that there is a significant effect on wages for those workers who received some form of computer training. These effects persist even when controlling for occupation and industry, and they exceed the wage effects of training in other subjects.
\end{abstract}

\section{Introduction}

A number of international studies have shown that there has been a growth in the use of computers at work and that workers who use computers earn more than those who do not. Because it is the more highly educated and skilled workers who are more likely to use computers, any wage premium for computer use contributes to the increasing wage gap between skilled and unskilled workers. Partly as a result, the current Government is keen on encouraging people to obtain the computer skills required to enable them to be part of the modern digital economy.

While large-scale survey data on wages and computer use in New Zealand are unavailable it is possible to examine the effect on wages of receiving computer-related training. In this paper we use data from the 1996 Education and Training Survey to examine the effect on wages of receiving computer-related training. The results suggest that there is a significant effect on wages for those workers who received some form of computer training. These effects persist even when controlling for occupation and industry, and they exceed the wage effects of training in other subjects.

\section{Previous Research}

The last decade has seen several empirical studies of the impact of the "computer revolution" on the wage structure. Such studies are needed because the effect of this new technological change on relative earnings could affect different categories of workers in various ways. If computing complements skills then it is likely to lead to an expansion in earnings differentials based on skill, whereas if it was a substitute it is likely to lead to compression in skill-based wage differentials (Krueger, 1993). For example in the United States it appears that

\footnotetext{
${ }^{1}$ Address for correspondence: Department of Economics, University of Waikato, Private Bag 3105, Hamilton, New Zealand. Fax: (7) 838-4331; Phone (7) 856-2889 email bdaldy@waikato.ac.nz or jkgibson@waikato.ac.nz .

Access to the data used in this study was provided by Statistics New Zealand in a secure environment designed to give effect to the confidentiality provisions of the Statistics Act 1975. The results in this study and any errors contained therein are those of the authors, not Statistics New Zealand. The financial support of grant UOWX0016 from the Foundation for Research, Science and Technology is gratefully acknowledged.
} 
skill-biased technological and organisational changes that accompanied the computer revolution have helped increase the demand for skilled workers and hence their wages since the 1970s (Autor, Krueger, \& Katz, 1998; Krueger, 1993). Krueger used three microdata sets from the 1980s to investigate the issue of whether employees who use computers at work earn more as a result of applying their computer skills, and whether this could account for most of the change in wage structure. $\mathrm{He}$ found that employees could earn 10 to 15 percent more if they used a computer at work. Computer use also explained between one-third and one-half of the increase in the rate of return to education, due to the fact that it is the as more highly educated workers were more likely to use computers at work.

There is, however, debate about the size and source of the wage premium that is associated with computer usage. For example, DiNardo and Pischke (1997) used information from three large cross-sectional surveys from Germany and initially found a similar wage differential for use of computers as was found by Krueger in 1993, rising from 11 percent in 1979 to 17 percent in 1992. However, further investigation showed that large wage differentials also existed when basic office equipment such as pens, pencils or calculators were used and this therefore raises doubt about whether it is computer use per se that is associated with higher wages. Doubts also arise from a study of the impact of new technologies (NT) on the wages of French workers, which found a wage premium of using NT of just 6 to 10 percent, depending upon previous experience with NT (Entorf \& Kramarz, 1997).

A basic difficulty in measuring the wage effect of computer use is that firms may allocate computers to their most able workers, so what is measured is the combined effect of computer use and ability. Panel data offers the possibility of resolving this issue because it allows unobserved individual heterogeneity to be controlled for. The computer wage premium for France and Germany was significantly reduced and became statistically insignificant when panel data were used (Entorf \& Kramarz, 1997; Haisken-DeNew, 1999). But in contrast to these results, panel estimation from the British National Child Development Study, 1981-91, indicate a wage premium for computer use of between 11 and 13 percent (Bell, 1996). These results suggest that wages are positively related to technical skills and that there is little evidence that unobserved characteristics of either the individual or the firm are driving the correlation (Bell, 1996).

An Australian study using data from the 1993 Survey of Training and Education found that there was a wage premium of between 12 and 16 percent if computer usage was included in the earnings function (Miller \& Mulvey, 1997). As well as including many of the standard variables related to an individual's education and work experience, this study also included information on English language proficiency, firm size, birthplace and union size, so the unmeasured and endogenous matching of productive workers with computers may have been controlled for.

\section{Data and Estimation Methods}

Although large surveys with data on workplace computer use and wages are not available in New Zealand, information on computer-related training and wages is available. Under the assumption that those workers trained to use computers do actually use them, such information can allow the affect of computer use on wages to be identified. The data used in this study come from the Education and Training Survey (ETS), which was a one-off survey, conducted by Statistics New Zealand as a supplement to the September 1996 Household Labour Force Survey (HLFS). It is the first major survey of job-related training in New Zealand. This paper uses the responses from respondent's aged 15-64 related to their participation in training provided by an employer, or more commonly known as in-house training. The survey also includes other variables to control for many of the individual characteristics that have been suggested by others to influence wages.

Although the ETS has a sample of 22,257 , a total of 10,443 respondents were either not employed or else had missing information on earnings and so were excluded from the analysis. Part-time workers $(n=2969)$ are excluded because it is difficult to know from the annual earnings variable whether these workers have low wages or low labour supply. Also excluded were 556 workers who had missing information on either training, years of schooling or other explanatory variables, leaving a final estimating sample of 8289 . The survey was weighted so all results reported below use the weights and correspond to the population rather than to the sample.

For each in-house training course (up to a maximum of four) the survey asked respondents about the main subject of the course, where "computing" was included as a choice along with eight other broad subject areas. For each training program completed, respondents could only choose one main subject from the list but by covering up to four recent training episodes the survey is able to handle those respondents who received training across several subject areas.

The distribution of training by subject matter is shown in Table 1. Thirty percent of the sample of full-time employed workers received some type of in-house or employer based training in the previous 12 months $(\mathrm{n}=2439)$. Because some employees attended more than one event over the survey period, a total of 3290 training episodes were recorded. The most common subject of training was Professional and Technical; with about ten percent of the full-time workforce receiving at least one training episode in this subject. The next most frequent subject matters for training were Health and Safety and then computing, with 6.5 percent and 5.5 percent of the workforce identifying these as the main subjects of one or more of their training episodes. This is likely to underestimate the extent of computer related training however, because some of the other subjects, such as "professional and technical" (which is the most frequent subject of training) and "clerical and office" are likely to have some computing component. In contrast to the 5.5 
percent of workers who attended a computer-related training course, just over one quarter $(27 \%)$ of fully employed workers attended a training session that was not explicitly computer related.

Table 1. Survey proportions of each type of in-house training.

\begin{tabular}{lc} 
Subject & Survey Proportions ${ }^{\mathrm{a}} \%$ \\
\hline Professional and Technical & 9.3 \\
Managing Others & 5.1 \\
Service and Sales & 4.9 \\
Health and Safety & 6.5 \\
Trade & 2.3 \\
Clerical and Office & 1.0 \\
Self Management & 3.1 \\
Orientation & 1.2 \\
Other & 1.4 \\
Any of above & 27.0 \\
Computing & 5.5 \\
Some in-house & 29.9 \\
\hline
\end{tabular}

Note: ${ }^{\text {a }}$ Proportions relate to the population and are based on the survey sample weights.

To measure the comparative effect of computer-related training on wages we start with a standard human capital earnings equation, where $(\log )$ annual earnings are a function of a quadratic in age, gender, ethnicity, marital status, years of schooling and months of tenure with the current employer. We also include controls for the worker's occupation and industry of employment. We expect that the addition of these controls will lower the measured return to computer training because part of the return to computer skills may be in enabling the worker to move to higher paying industries and occupations. But if there are unmeasured ability differences across occupations and industries the estimated effect of computer training will be biased upwards. Because we want to present the most conservative estimates, given the claims of upward bias in the previous literature, we estimate the within industry and within occupation wage effects.

The results of the basic earnings function are in column (1) of Table 2. These results come from an estimator that accounts for the weighted nature of the sample and for the categorical nature of the dependent variable (earnings were in 5 brackets $<\$ 14,000, \$ 14,001-\$ 22,000, \$ 22,001$ $\$ 29,000, \$ 29,001-\$ 39,000$ and $>\$ 39,000$ ). It appears that earnings are higher for males, and lower for workers from ethnic minorities, and higher for married workers, rise with age but at a diminishing rate, rise by about 4 percent for each additional year of schooling and by about 0.18 percent per month of tenure with the employer (or 2 percent per year). With the exception of the tenure effect, similar results to these have been reported previously in the New Zealand literature (Dixon, 2001; Gibson, 2000; Maani, 2000).

The results of the regressions that show the effect on earnings of receiving some form of in-house training are reported in column (2) of table 2. Four of the training variables have statistically significant effects on wages (indicating training in the subjects of Professional and
Technical, Managing Others, Computing and Trade). Those that received computer-related training have wages that are nearly 13 percent higher, all else the same $e^{2}$. This is the largest effect for any specific training subject. Even though this 13 percent wage premium is measured from training data, it is remarkably similar to the wage premia for computer use reported in other studies.

To get a firmer estimate of the wage premium for computer training relative to other subjects, the data on participation in training for all other subjects were collapsed into a single variable "not computing". This strategy enabled a more precise estimate of an 8 percent wage premium for training in subjects other than computing (this can be thought of as a weighted average across the other categories). A hypothesis test comparing the 13 percent wage premium for computer training to the 8 percent wage premium for training in other subjects indicated that the computer training effect was significantly higher $\left(\chi_{(1)}^{2}=4.49 p=0.03\right)$.

\footnotetext{
2 The percentage gain to the $j$ th dummy variable is derived from the coefficient for that variable, $\beta_{j}$ as $100 \times\left[\exp \left(\beta_{j}\right)-1\right]$ eg. $100 \mathrm{x}$ $\exp (0.121)-1=12.9$ or approximately 13 percent.
} 
Table 2. Earnings function without training, with any subject matter training and computer versus noncomputer related training.

\begin{tabular}{|c|c|c|c|c|c|c|}
\hline & \multicolumn{2}{|c|}{ (1) } & \multicolumn{2}{|c|}{ (2) } & \multicolumn{2}{|c|}{ (3) } \\
\hline Variable & Coefficient & $t$-value & Coefficient & $t$-value & Coefficient & $t$-value \\
\hline Intercept & 9.072 & 145.7 & 9.089 & 147.19 & 9.086 & 146.54 \\
\hline Male & 0.221 & 21.09 & 0.220 & 20.97 & 0.220 & 21.03 \\
\hline Maori & -0.051 & -3.2 & -0.050 & -3.16 & -0.050 & -3.12 \\
\hline Pacific & -0.120 & -6.38 & -0.115 & -6.17 & -0.114 & -6.1 \\
\hline Other $^{\mathrm{a}}$ & -0.089 & -3.78 & -0.082 & -3.61 & -0.084 & -3.67 \\
\hline Married & 0.065 & 6.1 & 0.062 & 5.84 & 0.062 & 5.83 \\
\hline Age & 0.048 & 17.54 & 0.047 & 19.87 & 0.047 & 16.84 \\
\hline $\operatorname{Age}^{2}(/ 100)$ & -0.001 & -16.59 & -0.001 & -15.85 & -0.001 & -15.85 \\
\hline $\begin{array}{l}\text { Years of } \\
\text { Schooling }\end{array}$ & 0.040 & 18.14 & 0.038 & 17.34 & 0.038 & 17.73 \\
\hline Tenure & 0.002 & 16.52 & 0.002 & 15.72 & 0.002 & 15.9 \\
\hline $\begin{array}{l}\text { Training subject } \\
\text { Professional and } \\
\text { Technical }\end{array}$ & & & 0.104 & 5.69 & & \\
\hline Managing Others & & & 0.094 & 4.24 & & \\
\hline Service and Sales & & & 0.015 & 0.76 & & \\
\hline Computing & & & 0.121 & 5.84 & & \\
\hline Health and Safety & & & 0.031 & 1.8 & & \\
\hline Trade & & & 0.06 & 2.06 & & \\
\hline Clerical and Office & & & 0.005 & 0.15 & & \\
\hline Self Management & & & 0.049 & 1.74 & & \\
\hline Orientation & & & 0.064 & 1.49 & & \\
\hline Other & & & 0.022 & 0.62 & & \\
\hline Not Computing & & & & & 0.074 & 6.94 \\
\hline Computing & & & & & 0.124 & 6.06 \\
\hline $\begin{array}{l}\chi^{2} \\
N\end{array}$ & $\begin{array}{c}\chi_{(25)}^{2} \\
8289\end{array}$ & 404.28 & $\chi_{(35)}^{2}=$ & $\begin{array}{c}498.15 \\
8289\end{array}$ & $\chi_{(27)}^{2}=$ & $\begin{array}{l}71.55 \\
8289\end{array}$ \\
\hline
\end{tabular}

Notes: Equations include dummies for occupation and industry, details available from authors. Estimates are weighted by population sampling weights and $t$-statistics are based on heteroscedastically-consistent standard errors

${ }^{a}$ Includes those who do not specify their ethnic group

${ }^{b}$ Equivalent full-time years of secondary school and post-secondary school educational study.

The next table focuses on the results for the sub-sample of those that received some form of in-house training $(n=2439)$. The interest in this sub-sample is that if more able workers receive training, as was suggested in other studies that used panel data (DiNardo \& Pischke, 1997; Entorf \& Kramarz, 1997), then restricting attention to this group of workers may remove this source of bias. The key result of this sensitivity analysis is to confirm the previous findings; otherwise the only difference is that the training subject related to trade no longer has a significant impact on employee's earnings. When comparing computing with all other subjects combined, there is a statistically significant difference in the wage premium for computing compared other subjects (11.6 percent versus 2.7 percent, $\left.\chi_{(1)}^{2}=8.0 \quad p=0.005\right)$. 
Table 3: Regressions coefficients for only for those that did some form of in-house training and corresponding $t$-values

\begin{tabular}{|c|c|c|c|c|}
\hline & \multicolumn{2}{|c|}{ Any Training } & \multicolumn{2}{|c|}{$\begin{array}{l}\text { Computer or non-computer } \\
\text { training }\end{array}$} \\
\hline Intercept & 9.023 & (73.06) & 9.005 & $(70.55)$ \\
\hline Male & 0.20 & (10.79) & 0.203 & (10.93) \\
\hline Maori & -0.062 & $(-2.18)$ & -0.061 & $(-2.11)$ \\
\hline Pacific & -0.087 & $(-2.12)$ & -0.086 & $(-2.08)$ \\
\hline Other $^{\mathrm{a}}$ & 0.065 & $(1.56)$ & 0.059 & $(1.41)$ \\
\hline Married & 0.061 & $(3.18)$ & 0.065 & $(3.37)$ \\
\hline Age & 0.061 & (11.03) & 0.062 & (11.14) \\
\hline $\operatorname{Age}^{2}(/ 100)$ & -0.001 & $(-10.41)$ & -0.001 & $(-10.57)$ \\
\hline Years of Schooling ${ }^{b}$ & 0.037 & $(9.71)$ & 0.041 & $(10.8)$ \\
\hline Tenure & 0.002 & $(8.67)$ & 0.002 & $(9.1)$ \\
\hline \multicolumn{5}{|l|}{ Training subject } \\
\hline Professional and Technical & 0.124 & $(5.21)$ & & \\
\hline Managing Others & 0.088 & $(3.82)$ & & \\
\hline Service and Sales & -0.011 & $(-0.42)$ & & \\
\hline Computing & 0.124 & $(5.42)$ & & \\
\hline Health and Safety & 0.002 & $(0.11)$ & & \\
\hline Trade & 0.009 & $(0.30)$ & & \\
\hline Clerical and Office & 0.013 & $(0.38)$ & & \\
\hline Self Management & 0.049 & $(1.75)$ & & \\
\hline Orientation & 0.056 & (1.34) & & \\
\hline Other & 0.005 & $(1.16)$ & & \\
\hline No Computing & & & 0.027 & $(0.73)$ \\
\hline Computing & \multirow{3}{*}{\multicolumn{2}{|c|}{$1254.10(35 \mathrm{dof})$}} & 0.110 & (4.2) \\
\hline$\chi^{2}$ & & & \multicolumn{2}{|c|}{1147.41 (27 dof) } \\
\hline$\tilde{N}$ & & & \multicolumn{2}{|c|}{2439} \\
\hline
\end{tabular}

Notes: Equations include dummies for occupation and industry, details available for authors. Estimates are weighted by population sampling weights and $t$-statistics in ( ) based on heteroscedastically-consistent standard errors

${ }^{a}$ Includes those who do not specify their ethnic group

${ }^{\mathrm{b}}$ Equivalent full-time years of secondary school and post-secondary school educational study.

\section{Conclusion}

This paper has shown that in New Zealand there is a wage premium to full-time workers who have received some in-house computer-related training even when controlling for various individual and employment characteristics that normally affect a person's ability to earn. Assuming that those workers trained to use computers do actually use them, this effect is consistent with estimates found in other countries. Most notably, the effect of receiving training in the subject of computing is much larger than the wage effect of other training subjects. This difference persists and in fact widens when the sample is reduced to include only those that received some form of in-house training. These results suggest firms that have sent employees on computer-related training courses have enabled those workers to improve their earnings and hence contributed to an increased dispersion in earnings.
The survey that was analysed in this paper is now six years old and hence it would be desirable if another similar survey was conducted in order to determine if there are any differences in who receives training and in particular if the returns to computer-related training have changed over time. In a previous paper we had found that there were significant differences by age, ethnicity and region of residence, especially urban versus rural differences, in who received some training (Daldy \& Gibson, 2001). Further research could examine the impact of computer-related training on workers from different ethnic groups and in different areas of residence in New Zealand in order to help identify whether the premium for computer training contributes to earnings inequality along ethnic and geographical dimensions as well. 


\section{References}

Autor, D., Krueger, A., \& Katz, L. (1998). Computing Inequality: Have computers changed the Labor Market? Quarterly Journal of Economics, CX111, 1169-1214.

Bell, B. D. (1996). Skill-Biased Technical Change and Wages: Evidence for a Longitudinal Data Set: University of Oxford.

Daldy, B. M., \& Gibson, J. K. (2001, Sept). Is Computing Different? Comparing the Determinants of Computer-related and other Subject Matter Training in New Zealand. Paper presented at the 30th Annual Conference of Economists, Perth.

DiNardo, J. E., \& Pischke, J.-S. (1997). The returns to computer use revisited: Have pencils changed the wage structure too? The Quarterly Journal of Economics, 112(1), 291-303.

Dixon, S. (2001). Work Experience and the Gender Earnings Gap. New Zealand Economic Papers, $35(2), 152-174$.
Entorf, H., \& Kramarz, F. (1997). Does unmeasured ability explain the higher wages of new technology workers? European Economic Review, 41, 1489-1509.

Gibson, J. (2000). Sheepskin effects and the returns to education in New Zealand: Do they differ by ethnic groups? New Zealand Economic Papers, 34(2).

Haisken-DeNew, J. P. (1999). Money for Nothing and Your Chips for Free? The Anatomy of the PC Wage Differential (Discussion Paper 86). Bonn: Institute for the Study of Labor (IZA).

Krueger, A. B. (1993). How computers have changed the wage structure: Evidence from microdata, 19841989. The Quarterly Journal of Economics, 108, 33-60.

Maani, S. (2000). Secondary and Tertiary Education Attainment and income levels for Maori and non-Maori over time (Working Paper 00/18). Wellington: New Zealand Treasury.

Miller, P., \& Mulvey, C. (1997). Computer Skills and Wages. Australian Economic Papers, 36(68), 106-113. 